\title{
"Misery Business?": The Contribution of Corpus-Driven Critical Discourse Analysis to Understanding Gender-Variant Twitter Users' Experiences of Employment
}

\author{
LEXI WEBSTER \\ Lancaster University / Manchester Metropolitan University \\ 1.webster3@lancaster.ac.uk / lexi.webster@mmu.ac.uk
}

\begin{abstract}
This contribution is a corpus-based analysis of gender-variant discourse on Twitter, exploring users' strategies for organizing their experience and understanding of employment. The data are two specialized corpora: (1) the biographies of each of 2,881 self-identifying gender-variant users; (2) c.4,000,000 tweets posted by those users. The corpora are analyzed using a sociocognitive approach to discourse analysis (Van Dijk, 2009, 2015, 2017). The biographies are used to determine the demographic make-up of the sample. An analysis of the corpus of users' tweets will explore, and attempt to explain, the activated discourses around aspects of employment (i.e. representations of the self-as-employee, co-worker relationships, employers, and experiences in employment). In considering the contribution linguistics can make in understanding gender-variant people's experiences of employment, the focus of this research is three-fold: (1) I consider the role of gender-variant users' cognitive organization of employment experience in either perpetuating or challenging marginalization in the workplace; (2) I consider the validity and reliability of a corpus-driven analysis in comparison to the credibility and validity of previous studies on the employment experiences of gendervariant people; (3) I consider the logical and ethical implications of considering only the roles of employers, policymakers, and co-workers in remedying marginalization in the workplace.
\end{abstract}

\section{The 'transgender experience' of employment}

If any one notion is cited in all research on the social phenomenon of 'transgender', it is that those people identifying as transgender are marginalized in society. Whilst this is in no way positive, it is certainly not surprising. Marginalization entails the consideration of a social group as peripheral and insignificant. Gender-variance is peripheral insofar as it is divergent from the societal norm of gender-sex congruence. Gender-variant people are insignificant in society insofar as they number so few: most estimates suggest gender-variant people make up significantly less than $1 \%$ of the population. Of course, this is dependent on how the researcher defines transgender in the research process - due to the difficulty of accessing data, most estimates only consider those who have undergone, or intend to undergo, medico-surgical intervention in order to align their physiology with their socio-psychological gender identity (e.g. De Cuypere et al., 2007). Others could include those who choose not to, or otherwise cannot, undergo medico-surgical intervention; others still might broaden the definition to include other gender-variant identities (i.e. agender, non-binary) - such estimates are yet to have been conducted and/or made public. A conservative estimate of the transsexual 
population, then, suggests 'prevalence figures' of between 1 in 19,000 and 1 in 45,000 for transfeminine individuals and between 1 in 30,400 and 1 in 200,000 for transmasculine (World Professional Association for Transgender Health, 2011). ${ }^{1}$ For the sake of perspective, that means transfeminine individuals likely comprise between $0.002 \%$ and $0.005 \%$ of the population and transmasculine individuals between $0.0005 \%$ and $0.003 \%$, based on population estimates of the United Kingdom (Office for National Statistics, 2016) and United States of America (United States Census Bureau, 2017). The employable population is even smaller; approximately one-third of the population of each the United Kingdom and the United States of America is not of working age (Office for National Statistics, 2016; United States Census Bureau, 2017). Distinguishing between smaller gender-similar groups in the gender-variant population, each with their own individual needs - as is called for in much research (including some of my own) - would reduce the number even further. Is it realistic to expect that policymakers and employers respond to the needs of micro-minorities? More to the point: need they?

Previous research primarily focuses on the implications of the 'transgender experience' of employment on workplace policy, employer's actions, and employment legislation. However, the logic of drawing conclusions from data is often unclear and responsibility for remedying marginalization is placed anywhere but in the hands of the gender-variant employee. Moreover, there is a trend for ambiguously worded results and the use of pseudo-statistics that have the effect of masking potential areas for either concern or celebration. For example, Grant et al. (2011) state that $90 \%$ of their respondents "[experienced] harassment, mistreatment, or discrimination on the job or took actions to avoid it" (Grant et al., 2011: 3, emphasis added), masking the number of those who experienced discrimination and those who feared discrimination - two very different notions. Indeed, where results show the realization of a gender-variant participant assuming responsibility, or at least acknowledgment, of their own role in their negative experience of employment, they are dismissed out of hand as being a symptom of some neoliberal, post-Fordist, and transphobic global agenda (see Irving, 2017: 171). It is crucial for us as researchers to be critically aware of our own contribution to discourses of in/equality; it is especially prudent to consider our use of language, our ideological biases, and the cognitive organization of our own experiences when conducting research and theorizing the remedy for societal imbalances or inadequacies. Accuracy, awareness, and objectivity are paramount.

I aim in this paper to contribute to the scholarship on gender-variant people's experiences of employment by conducting a corpus-driven cognitive linguistic analysis of gender-variant Twitter discourse. The contribution is intended to be three-fold: (1) I consider the contribution of linguistics in exploring the role of gender-variant users' cognitive organization of employment experience in either perpetuating or challenging marginalization in the workplace; (2) I consider the validity and reliability of a corpus-driven analysis in comparison to previous studies on the employment experiences of gender-variant people; (3) I consider the logical and ethical implications of considering only the roles of employers, policymakers, and co-workers in remedying marginalization in the workplace.

\footnotetext{
${ }^{1}$ Transfeminine individuals are those who were born with male sexed physiology and have a feminine gender identity; transmasculine individuals are those born with female sexed physiology and who have a masculine gender identity.
} 


\section{A review of studies on the 'transgender experience' of employment}

I am primarily concerned with the lived employment experiences of gender-variant people, as opposed to hypothetical scenarios or abstracted case studies. Thus, rather than a comprehensive review of literature theorizing on discrimination - or not - against gendervariant employees from legal (Dunson III, 2001) or human resource management (Davis, 2009) perspectives, this paper specifically considers empirical research conducted with the aim of understanding and explaining the employment experience of gender-variant people. In this section, I use six studies focusing specifically on the 'transgender experience' of employment to formulate a critique of the existing scholarship on the topic. Each of the studies was published within a decade of this contribution's writing (i.e. 2007-2017), and all consider the general experience of gender-variant employees. I excluded studies from the review whose focus was not on the general gender-variant experience of employment. Examples of why studies were not considered in the review include: the research collectivizes 'transgender' within a study on 'LGBT' experiences of employment (i.e. Bell et al., 2011; Göçmen and Yılmaz, 2016); the researchers' focus is on the applicability of methods instead of results (i.e. Brewster et al., 2012), the research context is narrowed beyond the general experience of employment by gender-variant people (e.g. exploring specific fields of employment - Dietert and Dentice, 2015; using specific groups under the 'transgender umbrella' as units of analysis - Dietert and Dentice, 2009; Law et al. 2011; Dispenza et al., 2012). I did, however, include studies in the review that specifically sought to explore discrimination against gender-variant employees in the workplace. Despite my initial reluctance to include such studies, I quickly found that without considering them there would be no review: there is an evident ideological zeitgeist within research on gender-variant employees' experiences within the last decade that assumes discrimination from the outset (see also Brewster et al., 2014).

Given the ubiquitous reference to the marginalized paradigmatic transgender person and the need to amend practices that reproduce such marginalization, many - if not all - of the studies reviewed in this section can be considered emancipatory research: the researchers seek to address and, in turn, redress some societal imbalance (i.e. discrimination against gendervariant employees, or job applicants). Emancipatory research is ideological in nature (see Lather, 1986). At the very least, scholars conducting research with emancipatory aims do so from an ideologically-informed 'political position' that in turn informs methodology (Danieli and Woodhams, 2005). This is by no means inherently negative. However, as advocates for the emancipation of the socially oppressed, such researchers should be critically aware of the ideological bias inherent in emancipatory research and its implications for the interpretation of data, representation of findings, and reception of research by stakeholders. In addition to ideological bias that may affect the trustworthiness (i.e. validity, credibility) of studies, emancipatory research is as susceptible to other threats to research accuracy as any other paradigm. In the following subsections, I will first critically evaluate the validity and reliability of the aforementioned studies before exploring the logical and ethical implications of the research design and conclusions. 


\section{Validity and rigor in research design}

Validity is primarily deemed relevant only to positivism and quantitative research; its equivalent counterparts in qualitative research are "quality, rigor and trustworthiness" (Golafshani, 2003: 602). Given that the studies reviewed in this section comprise both quantitative and qualitative methods, and in order to defease objections to such value-laden lexis as 'trustworthiness' and 'quality', I will refer to validity and rigor interchangeably when evaluating whether a study/method measures what it is intended to measure or observe.

\section{Self-report methods}

Self-report methods are notorious for potential biases, which constitute threats to the validity of a study. Some of the more obvious forms of bias in self-report methods include acquiescent response, extreme response, image/impression management, respondents' introspective ability, and other response biases (see Paulhus and Vazire, 2007). In the context of business settings, much like the context of the studies reviewed herein, self-report bias may indeed "hinder the development of theories of organizational behavior" (Donaldson and Grant-Vallone, 2002: 245). All six studies use some form of self-report method, which is unsurprising given the context and aims of the research. Five use interviews (Schilt and Connell, 2007; Budge et al., 2010; Ozturk and Tatli, 2016; Irving, 2017; Mizock et al., 2017), and one a questionnaire (Brewster et al., 2014).

Only one paper explicitly discussed the potential effects on the validity of the self-report methods used; those effects were dismissed outright without explanation (Schilt and Connell, 2007: 598). However, there was some implicit discussion of the impact of research conditions on the validity of self-report data in two of the studies. Budge et al. (2010) considered the potential impact of the researchers on the responses of participants; specifically, they questioned the willingness of participants to "share their experiences" with "female-bodied, female-identified researchers" and whether participants would "believe that [the researchers] could understand [those] experiences" (Budge et al., 2010: 3). Again, the researchers chose not to explain how those potential concerns for the validity of the research might affect the results or how they might be overcome in the research process. Mizock et al. (2017) implied an understanding of potential concerns for validity via their utilization of experts - one expert in research on transgender, who "[verified] the cultural competence of the interview questions", and two in "research on mental health, stigma, and qualitative interviewing" (Mizock et al., 2017: 285) - in crafting the interview guide and codebook used in their study. Both may go some way towards improving the validity of the research. The former may control for response bias, insofar as questions are based on familiar sociocultural knowledge and assumptions, which can protect against misleading questions on the part of researchers and misunderstanding on the part of respondents (thus, improving validity). The latter may improve the construct validity of the research, insofar as the study measures/observes what it claims to be measuring (i.e. stigma). However, we are not invited anywhere in the paper to view the interview guide, nor do we have any explanation regarding what the experts suggested were appropriate ways of maintaining an apparent transgender cultural competence or for measuring/observing stigma.

The use of experts in the research design process and the apparently inconsequential consideration of participants' feelings towards researchers do not account for all threats to 
validity arising from self-report methods in the studies. The ideological aims of some of the studies constitute presuppositions about the state of the world - for example, coping with transphobia in employment (Mizock et al., 2017) presupposes that transphobia is inherent in gender-variant employment experiences, and demonstrating the "interconnectedness between proper gender expression and immaterial labour, negative affects (e.g. anxiety and depression), and the broader dynamics of socio-economic uncertainty" (Irving, 2017: 169, emphasis added) presupposes that a post-Fordist system of economic production engenders no positive affects within the gender-variant population. Alone, these ideologically-grounded research aims can serve to reproduce the hegemonic ideology of gender-variant marginalization. In combination with self-report methods, they can constitute threads to validity and contribute to response biases, particularly those pertaining to social desirability and the participant responding with what they assume the researcher wants to hear. Impression management, or social desirability distortion, may constitute "'faking bad' to obtain [...] sympathy, or [...] 'faking good' to make a good impression" (Richman et al., 1999: 755); either way, the validity of the results is threatened by this form of response bias, which is not indeed accounted for, or is sometimes not at all acknowledged, in any of the studies. For example, in attempting to explain negative workplace experiences and outcomes (i.e. job loss, unemployment, lack of promotions, lack of salary increases), respondents might misattribute responsibility to employers, co-workers, and workplace policy in order that the researchers maintain a positive perception of the participant, or to garner sympathy from researchers in accordance with the hegemonic marginalization and discrimination of the gender-variant employee.

A lack of controls for response bias in self-report methods, and a worrying dearth of consideration of the validity of measures/observations, entails questionable rigor on the part of the studies reviewed herein. Each of the studies aim to observe and explain differing issues: gender identity discrimination (Ozturk and Tatli, 2016), achieving gender identity interactionally in "open workplace transitions" (Schilt and Connell, 2007: 596), issues for gender-variant employees in the workplace and the reasons for gender-variant "un(der)employment" (Irving, 2017: 169), general complexities of on-the-job gender transition (Brewster et al., 2014), the impact of gender-variant identity on career decision-making processes (Budge et al., 2010), and coping with transphobia in the workplace (Mizock et al., 2017). Many of the observations and measures made in the studies refer to respondents' feelings or interpretations of actions, which can obscure the practical realities in the workplace. Hence, rather than measuring/observing the practical reality of workplace experiences of gender-variant people, the studies seem primarily to be measuring how participants feel about or respond to workplace experiences, which Spector (1994: 390) deems an advantage of selfreport methods in research on organizational behavior. Whilst this may be appropriate in the observation of issues in the workplace and the effects of gender identity on career decisionmaking decisions, it does not seem particularly appropriate in the other studies - for example, the practical reality of gender-based discrimination should be considered over feelings regarding potential discrimination, and transphobia should be determined as a practical reality of employment in gender-variant employees' experiences before considering the feelings and coping strategies around transphobia. 


\section{Self-selection and snowball sampling}

Another element of research design that affects the validity of a study, particularly external validity - or, the generalizability, is the sampling method. Of those that explicitly stated their sampling methods, one used self-selection sampling only (Brewster et al., 2014), and three used a combination of self-selection and snowball (Schilt and Connell, 2007; Ozturk and Tatli, 2016; Irving, 2017). For self-selection methods, researchers primarily used community listservs, activist networks, and online forums as invitation channels. Snowball sampling in the studies was either researcher-centered (Schilt and Connell, 2007), participant-centered (Irving, 2017), or a combination of the two (Ozturk and Tatli, 2016). Budge et al. (2010) and Mizock et al. (2017) do not specify the sampling method(s).

Not specifying the sampling method used is a red flag for the reliability of a study, insofar as reliability refers to the replicability of a study; not knowing the means by which participants were recruited renders other researchers incapable of accurately repeating the study. Similarly, without comprehension of the sampling method, it is impossible to ascertain the samples' potential threat to reliability or external validity. As such, one can only assume the studies' inherent lack of reliability - due to the impossibility of replication - and validity - due to the impossibility of ascertaining the relationship between the researchers and the participants.

Self-selection sampling has its own effects on the external validity of a study. Interestingly, none of the studies using self-selection sampling refer to the method as self-selection; rather, they refer to it as 'purposive sampling' (Ozturk and Tatli, 2016) or as recruitment (Schilt and Connell, 2007; Brewster et al., 2014; Irving, 2017). One of the primary threats to validity that self-selection poses is that of self-selection bias - self-selection is a non-random sampling technique for which it is impossible to "construct unbiased estimates", thus raising questions about the accuracy and rigor of the research (Bethlehem, 2010: 162). Of course, it may be that this method of sampling is one of the only appropriate sampling methods for using microminorities, such as the gender-variant population, as units of analysis in research. However, self-selection can lead to bias insofar as respondents may engage with a study "for reasons that are systematically related to the behaviors or attributes under study" (Lavrakas, 2008: 809) - that is, respondents to these studies may self-select to participate because they have encountered particularly extreme workplace experiences that they attribute to their gendervariant identity/status. This is particularly concerning when considering the channels used for inviting self-selection in the studies. Those engaging with online communication media specifically aimed at a gender-variant user-audience are likely to consider their gender-variant status a central element of their identity. Additionally, those engaging with activism will likely participate in the research as a means of performing activist work, giving extreme examples of discrimination in order to highlight the plight of the gender-variant employee.

Snowball sampling shares the disadvantages of self-selection: it is a non-random sampling method, is unrepresentative and not generalizable. It can also lead to skewed data insofar as interviewees or researchers might ask their contacts to contribute because they have a specific extreme workplace experience in mind that contribute to the ideological aims of the study, thus potentially impacting validity in much the same way as self-selection. Justification for the snowball sampling method is only offered in Ozturk and Tatli (2016), who cite initial difficulties in accessing gender-variant respondents and the method's appropriateness for "reaching out to vulnerable populations" (Ozturk and Tatli, 2016: 787). The equation of 
gender-variance with vulnerability is problematic, arguably constituting a reproduction of the hegemonic marginalization of and discrimination against gender-variant individuals, which seems counterintuitive when considering the research aims.

Of those reviewed, no other study justified their choice of sampling method, which is not atypical in research utilizing snowball sampling (Biernacki and Waldorf, 1981). However, five of six studies did describe their participants to some extent. Even the studies who provided no information on the sampling method gave some descriptions of the makeup of their sample, with reference to race/ethnicity, employment status, and marital status (Mizock et al., 2017), or to educational attainment, sexual orientation and income range (Budge et al., 2010). Other descriptions of participants included geographical location (Brewster et al., 2014; Ozturk and Tatli, 2016), and occupation in terms of professionalism (Schilt and Connell, 2007) or industry (Ozturk and Tatli, 2016). Irving (2017) provided no information on the composition of his sample.

From known information about the sample, we can deduce at least some factors that might either reduce or improve the external validity - i.e. generalizability - of the study. Brewster et al.'s (2014) participants, though self-selected, also had to confirm they met specific conditions set by researchers; those conditions were that participants were to be employed at the time of the study, were 18 years or older, and "self-identified as 'somewhere on the transgender spectrum'" (Brewster et al., 2014: 162). No other studies explicitly mentioned conditions for participation. Of course, an implied prerequisite for participation in each of the studies was the respondents' self-identification as gender-variant. Similarly, other conditions are implied in the description of demographic characteristics of the respondents. A particularly relevant example of implicit conditions for the sample of each study is employment status; each of the studies claims to either measure or observe workplace experiences, so knowledge of differences in employment status would be useful in such explorations. Four of the six studies included only employed participants (Schilt and Connell, 2007; Budge et al., 2010; Brewster et al., 2014; Ozturk and Tatli, 2016), and Mizock and Mueser's (2014) sample included employed, unemployed and retired respondents. Again, Irving (2017) provided no information. The inclusion of only employed participants in research on workplace experiences necessarily affects the generalizability of the results and skews the data. Denying unemployed people access to participation in the study constitutes a reproduction of the hegemonic, some might say post-Fordist, or neoliberal, ideology that human worth is primarily determined by employment status. Additionally, reducing the sample by introducing conditions that exclude a significant proportion of the target population - gender-variant unemployment rates were three times higher than the unemployment rate in the U.S. population in 2015 (James et al., 2016) - seems counterintuitive to the research aims, especially given that the justification for self-selection and snowball sampling solely relies on the difficulty of accessing the population for their vulnerability and insignificant number.

\section{Interpretation of data and representation of findings}

Whilst unconscious, or unintended, ideological bias is evident in both data collection and sampling methods, it is most apparent in the analysis, interpretation, and representation of data. As researchers, it is imperative that we are aware of the implications our analysis, interpretation, and representation has on the reception of research and for wider society. Of particular importance is accuracy in the linguistic representations of findings - whilst analysis 
and interpretation are impacted mainly by ideological bias, it is imperative that linguistic representations of data and findings are accurate. Language use and, by extension, linguistic choice are inherently ideological (Lemon, 2003); it is, therefore, prudent to consider specifically the implications of our linguistic choices on the representation of data/findings and on the reception of the research.

This is especially true when representing quantitative data, given that researchers give an "impression of authority" when representing figures (Overton and Van Diermen, 2014: 54) misrepresentation of quantitative data could greatly impact the interpretation of results not only by researchers but by the consumers of research. A particularly worrisome aspect of the reviewed studies is the misuse of quantitative/quantified evidence: the misrepresentation of data via the use of misleading statistics, unqualified quantitative evidence, or representing qualitative data using arguably quantifying terminology. Brewster et al. (2014) use large ranges to denote the typicality of experiences (i.e. $20 \%-49 \%$ - some participants; $50 \%-79 \%-$ most participants), which is evidently an example of skewed statistics: a factor occurring in $50 \%$ of cases would be interpreted and represented as being typical of the sample, whilst a factor occurring in 49\% of cases would be represented as occasional (Brewster et al., 2014: 263). Hence, the former would be considered characteristic of gender-variant employment experience and the latter an infrequent occurrence in gender-variant employment experience. Similarly, Budge et al. (2010: 11) referred to "a number of individuals" experiencing job loss due to identity. In addition to this claim being completely unverifiable and unevidenced, the generalized and indeterminate number of students provides no solid quantitative evidence (despite relying on a 'number', as quantitative evidence does); in combination with its prominence in the analysis, as a theme in the findings, the linguistic representation of evidence as indeterminately quantified invites the reader to interpret the results as significant (despite the lack of statistical, or even strictly numerical, evidence). The unqualified quantification of findings via indeterminate number is also present in Mizock et al.'s (2017) and Schilt and Connell's (2007) studies - each of the three studies includes indeterminate numerical references including few, many, and several. Representing findings as thematic also has a quantifying affect, insofar as themes invite interpretations of recurrence - this strategy of data representation is present in all but Schilt and Connell's (2007) study, with only Brewster et al. (2014) using numerical evidence, however misleading, to evidence such claims for themes in the employment experiences of gender-variant individuals.

Ambiguously worded qualitative findings are also factors in the misrepresentation of data, affecting the reception of results and betraying the ideological bias of the researchers. This is particularly evident in the interpretation and explanation of qualitative evidence. Examples of the misleading interpretation and explanation of qualitative data can be found in the studies reviewed. Ozturk and Tatli (2016) quote evidence from a participant who claims ignorance of gender-variance has rendered her unemployable in accounting, and actively accuses previous interviewers of discrimination based on gender identity (Ozturk and Tatli, 2016: 789); this claim is without evidence and based solely on the participants' reading of the situation. The researchers go on to interpret the qualitative evidence as a factual representation of practical reality in the workplace, generalizing their explanation of anti-transgender discrimination to all 'organizations' via the use of which, which describes all organizations as being ignorant of gender-variant needs (as opposed to the post-modification that, which would denote a subset of organizations as having that specific characteristic). Whether deliberate or not, this constitutes an inaccurate explanation of the data, determining practical reality from a 
participant's unevidenced and unverifiable claims. Another example can be found in Irving's (2017) research; the researcher interprets one respondent's acknowledgment that employers are not intentionally discriminatory against gender-variant candidates as being "hesitant to accuse potential or past employers of transphobia" (Irving, 2017: 170), an interpretation not supported by the evidence the researcher provides. Indeed, immediately preceding his charge of hesitation on the part of gender-variant people, he provides an example which can easily be argued as constituting an explicit accusation of transphobia. Irving (2017) is, consciously or otherwise, reproducing the hegemony of gender-variant individual's powerlessness in society by referring to his respondents' hesitance and not accurately explaining the qualitative evidence. More examples of this trend of misrepresenting qualitative data can be found again in Budge et al.'s (2010: 11) evidence for the theme of "job loss due to transgender identity", and Schilt and Connell's (2007) interpretation of a senior staff member's comments about a gendervariant employee's appearance as a "[border] war between gay men who do drag and transwomen" (Schilt and Connell, 2007: 609) and comments about her behavior as reflective of his own gendered ideology. It is equally important to note that the researchers, including Schilt and Connell (2007), accurately interpret the qualitative evidence as respondents' interpretation of events; this is particularly prevalent in Mizock et al.'s (2017) study, but also noticeable in Brewster et al. (2014) and some of Budge et al.'s (2010) explanations.

\section{Logical and ethical implications of interpreted findings and conclusions}

The logical conclusions made from the interpretation of both qualitative and quantitative data have specific implications on the discourse of inequality permeating research on and the lived experience of gender-variant individuals. The logical implication is the relationship between two propositions, and equivalent to entailment; if a conclusion is entailed by the premises, the reasoning is logically valid (see Cheng, 1996). Hence, the conclusions of a study are logically valid if, and only if, they are entailed by the data or findings (i.e. premises) of that study.

The conclusions made in some of the studies reviewed herein are not logically valid; it is prudent to note that conclusions are not necessarily argued in the section of a paper often titled 'Conclusions', rather, conclusions can be made in interpreting and explaining findings. The findings, as premises, might also be considered to entail implications for future practice (conclusions). Returning to the example in the above section from Ozturk and Tatli (2016), where the researchers concluded that one person's interpretation of negative interview outcomes as being due to anti-transgender discrimination equates to all organizations being ignorant of gender-variance and the specific needs of the gender-variant population, it is evident that the premises (i.e. the participant's claim) do not entail the conclusion. Similarly, Irving's (2017) conclusion that participants were hesitant to levy the charge of transphobia against their employers is not entailed by the premises (i.e. the qualitative evidence provided). In the first example, the suggested entailment is that the feeling of discrimination logically entails the existence or practice of discrimination. In the second, that not using specific terminology or specifically attributing no ill-intention logically entails that the participants were hesitating to accuse employers of transphobia. The relationship between premises and conclusions in these examples is evidently not one of entailment, or logical implication. It can be argued that logic is substituted for ideology. 
Across all studies with specific sections dedicated to 'Implications', there is an attempt to imply that negative employment experiences are the sole responsibility of employers and policymakers to fix; indeed, it is the responsibility of any other entity than the gender-variant employee/candidate. Ozturk and Tatli (2016) place the burden of ameliorating gender-variant employment experiences on human resource management policy, Brewster et al. (2014) on employers implementing "gender-sensitive practices" and activists petitioning for the implementation of "trans-affirmative policies" (Brewster et al., 2014: 168), Budge et al. (2010: 15 ) on counselling psychologists accommodation of the "unique challenges" faced by gendervariant employees during gender transition, and Mizock et al. (2017: 292) again on "transaffirmative employment practices". No study implies any positive course of action for gendervariant employees or candidates to ameliorate their experiences or maximize the potential for successful and positive employment outcomes. Given that the primary measurement/observation in the studies are employees'/candidates' feelings about, or responses to, employment experiences, it does not immediately appear logically valid that premises based on feelings (as opposed to practical reality) entail conclusions affecting practice.

The conflict between attributing gender-variant participants' potentially biased self-reported experience as an objective account of practical reality and attributing blame or responsibility on employers for remedying the situation is not only one of logic; it also presents a conflict of ethical implications - or the moral consequences for wider society. Firstly, researchers must consider that the reliance on societal elites (i.e. corporate organizations, policymakers) to ameliorate a negative situation reproduces the hegemonic marginalization and social powerlessness, or lack of agency, of gender-variant individuals. Conversely, attributing expert status to gender-variant individuals on the practical realities of workplace experiences, reflects the true ideological aim of the research to emancipate those same individuals from social oppression. As contradictions, those two implications do not entail one another. Hence, the rigor of such studies called into question once again; specifically, the studies' moral rigor.

The ethical implications also extend to how employers and policymakers are represented. Despite positive practical realities being referenced in all but Ozturk and Tatli's (2016) study, those studies with specific 'Implications' sections deferred to the impact of negative feelings in determining the responsibility of organizations, policymakers, co-workers, and activists in ameliorating the employment experiences of gender-variant employees/candidates. This il/logical reasoning represents an epistemological standpoint at odds with the practical reality of workplace experience, arguably constituting scaremongering and propagating those very negative feelings that they seek to ameliorate through the implementation of policy. Additionally, given that the existence of policy has largely no bearing on practice, it is difficult to imagine how such conclusions will effect positive change on the apparent fear of discrimination held by gender-variant employees/candidates.

\section{Methodology}

This section contextualizes and justifies the methodological choices made in my own study on gender-variant individuals' employment experiences. Specifically, this study aims to understand and explain the organization of employment experiences in gender-variant individuals' cognitive models. Throughout this section, I will evaluate my own methodological choices in much the same way as the above section: in terms of validity and 
reliability. I will explore the logical and ethical implications in the concluding section of this contribution.

\section{Data: collection, contextualization, and considerations}

The data comprise two specialized corpora, which were compiled as datasets for my doctoral thesis: (1) biographies of 2,881 self-identifying gender-variant Twitter users; (2) c.4,000,000 tweets from those users. The biographies were primarily used to determine the demographic make-up of the sample. I collected the data by mining the followers of eight micro-celebrity Twitter users for those who met the following conditions: (1) their profile was publicly accessible to any Internet-user; (2) their biography included reference to personal gendervariant identity. ${ }^{2}$ Whilst this is by no means a self-selected sample, the means of data collection might arguably constitute snowball sampling insofar as subjects were found via their affiliation with publicly-known gender-variant micro-celebrities. Thus, the data may suffer from the same threats to validity as any other sample recruited via the snowball method. The conditions for data collection, specifically condition (1), disallow for the inclusion of those users who do not specifically refer to gender-variant identity in their biographies, which potentially constitutes a threat to the external validity of the study. As with the studies reviewed above, the reason for the condition is mainly due to the inaccessibility or invisibility of the target sample/population. However, the sample is much larger than the studies reviewed herein (and many other studies besides), constituting $0.001 \%$ of Twitter's 330million 'monthly active users' (Statista, 2018). Extrapolating this percentage to the population would indicate that 1 in 114,543 Twitter users are gender-variant. The average of the extremes of the estimated transsexual population in the UK and USA are 32,000 (transmasculine) and 115,200 (transfeminine). The estimated gender-variant population of Twitter, after extrapolation from the users in my dataset, is within the range of those two averages; hence, it can be argued that the data is representative of the gender-variant population, which increases the external validity of the sample. The data might also be considered self-report data: users are entirely agentive in the posts they make public, and the data may still be prone to social desirability bias. However, given that the users made those posts public without knowledge of the intended aims of this study, it is unlikely that they will be generating content with the aims of studies like mine in mind. Thus, some elements of response bias are mitigated.

I categorized the sample into six groups based on gender-similarity: (1) transfeminine; (2) transmasculine; (3) transsexual; (4) transvestite; (5) non-binary; (6) transgender. Categories (1) and (2) denote feminine or masculine gender identity not congruent with natal sexed physiology but without reference to transsexuality, category (3) denotes users whose biographies contain specific reference to transsexuality (whether masculine or feminine), and category (5) includes users whose biographies reference gender-variance without specifying either binary or non-binary gender identities. Categories (4) and (5) are self-explanatory. The data comprises 992 transfeminine users (34\%), 461 transmasculine users (16\%), 171 transsexual users (6\%), 277 transvestite users (10\%), 364 non-binary users (13\%), and 616 transgender users $(12 \%)$. Again, this reflects the estimates of the general population of gender-variant individuals insofar as transfemininity is more prevalent than transmasculinity.

${ }^{2}$ The term 'micro-celebrities' refers to those who have gained celebrity status via social media (Khamis et al., 2016: 6). 
Of those categories, $40 \%$ of transfeminine users, $43 \%$ of transmasculine users, $41 \%$ of transsexual users, $10 \%$ of transvestite users, $49 \%$ of non-binary users and $58 \%$ of transgender users indicated some form of employment or occupation in their biography. The average percentage of the employed user-group population is $40 \%$. Evident outliers are the transvestite user-group, who are underemployed, and the transgender user-group, who are overemployed. Of course, because Twitter biographies usually reflect only users' most salient identity features (Volkova et al., 2015), the mention of employment/occupation in biographies does not necessarily reflect the practical reality of users' lives - many more may be employed who do not mention their job role or employment status (equally, many users may not be paid for the job role they claim to have - they may more accurately be referred to as hobbyists in particular fields).

Despite distinguishing between general gender-similar categories of the user in describing the demographic make-up of the sample, the analysis will not factor in inter- and intra-gender differences between users' employment experiences. As a preliminary exploration of the contribution of linguistics to research on gender-variant employment experiences, it is much more prudent to establish a 'baseline' of the gender-variant employment experience (as opposed to delving into the specificities of intra-minority differences). The following section will explain the analytical framework and method.

\section{Analytical framework: methods, models, and morals}

In order to explore the cognitive organization of gender-variant individuals' experiences of employment, I use a corpus-driven method for conducting a sociocognitive discourse analysis. Instead of approaching corpus data with a priori hypotheses, corpus-driven linguistics (CDL) prioritizes the role of the corpus in formulating such hypotheses regarding language use (Tognini-Bonelli, 2001; McEnery and Hardie, 2012). Using a corpus-driven approach to the study of employment discourses in gender-variant Twitter users' language use would mitigate, or control for, biases in research design; specifically, it controls for potential researcher bias in the formulation of hypotheses or the creation of materials for eliciting response from respondents (e.g. interview guides, survey items). Hence, the thread to validity made by researcher bias is largely mitigated. Of course, a potential issue with this approach to linguistic analysis is the possible lack of relevant data - fortunately, that is not the case in this particular study, although it should be accounted for in other applications of corpus-driven methods for linguistic analysis.

Sociocognitive approaches to discourse analysis explore specifically the relationship between discourse and society, which is mediated by cognition, in order to explore shared cognitive models between social groups (Van Dijk, 2009, 2015, 2017). Cognitive models are the subjective organization of personal experience (Lakoff, 1987). Given the study's aim to explore the cognitive organization of gender-variant employment experience, using a sociocognitive approach to discourse analysis is fitting - the method of analysis fits what the study seeks to observe/measure, and so is a potentially valid method. The primary proponent of sociocognitive discourse studies (SCDS), Van Dijk, proposes three key elements of the approach: local meanings of specific lexical items, semantic macrostructures, and "subjective mental representations" (Van Dijk, 2009: 66). Whilst the first of the three elements is selfexplanatory, the second refers to "the global meanings, topics or themes" of the discourse 
under observation (Van Dijk, 2009: 68), and the third to such cognitive structures as attitudes and ideologies present in the discourse.

The three elements correspond somewhat directly with the key components of a corpus analysis: keywords, collocates, and concordances. Keywords are those lexical items that are characteristic of one corpus, in comparison with another (Rayson and Garside, 2000), are measured for statistical significance using log-likelihood ratio, and their analysis directly corresponds to the analysis of lexical items for local meaning. Groups of keywords indicate semantic macrostructures. Keywords in this study were determined in reference to a random sample of 440,154,502 tweets from the corpus of tweets within the Stanford Large Network Data Collection (Leskovec and Krevl, 2014), which does have some impact on the validity: the data from the corpus were all originally posted to Twitter in 2009, potentially skewing the keywords found in the specialized gender-variant Twitter corpus. Following the initial keyword analysis, I analyze keywords' collocates - collocation is the "above-chance frequent co-occurrence of two words in a pre-determined span" (Baker et al., 2008: 278). Collocates are only considered truly so if they measure at a conventional rate of significance for at least two measures (Baker, 2014); in the case of this study, I measure collocation using mutual information (MI) scores and $t$-scores - the conventional threshold for the former is $\mathrm{MI} \geq 3$ and for the latter is $t \geq 2$. Again, individual collocates can be analyzed for local lexical meaning, and groups can be categorized into semantic macrostructures. While the analysis of keywords and their collocates are primarily quantitative measures for revealing patterns in corpora (Gabrielatos and Baker, 2008) that can secondarily be analyzed qualitatively, the final stage of analysis - concordance analysis - relies primarily on qualitative evidence (though, of course, the data can be quantified). Concordances are "instances of a word or cluster in its immediate co-text" (Baker et al., 2008: 279) and provide the richest data for the qualitative analysis of cognitive structures. Having detailed the analytical method, the following section will apply those methods to the specialized corpus of gender-variant users' tweets.

\section{Findings and Discussion}

Comparing the specialized gender-variant Twitter corpus with the reference corpus yielded 602 keywords with a log-likelihood ratio of \pm 3.84 (statistically significant at the $95^{\text {th }}$ percentile, or to $p<0.05)$ that either contain conceptual meaning in the semantic domain of work/employment or represent a functional occupational title. For the purpose of analysis, I focused on those keywords that are more indicative of general employment practices (e.g. work, worker, employee, employer), rather than specific job titles or functions - this analysis will better facilitate the aims of exploring a more generalized view of gender-variant users' cognitive organization of employment experiences, as opposed to employment experiences in specific industries or fields of work. The keywords can be broadly categorized into the macrostructures: paid work, unpaid work, staff, wages, unionization, and organization.

Each keyword yielded several thousand collocates; after accounting for those that did not meet the criterion of conventional significance in both collocational measures, the numbers far exceeded what could be sufficiently analyzed in a study of this scale. As such, I reduced the number of collocates by considering only those that co-occur in at least $5 \%$ of occurrences of the keyword as salient for the analysis. Additionally, given that grammatical item "can obscure [...] discourses that might be of interest" (Hardaker and McGlashan, 2016: 86), I removed grammatical items (e.g. $a$, as, of, the, etc.) from the collocational analysis. I consistently 
applied this method across each keyword, thereby maximizing the reliability of the analysis. After identifying the local lexical meanings of collocates, and identifying the macrostructures at work, I removed from the analysis those keywords whose collocates indicated discourse structures not focused on employment (e.g. slave, firing). The generic verbs work and worked were skewed by their use in other constructions not pertaining to employment (e.g. 'working out', non-human agents and processes 'working' correctly, etc.). Instead, I focused on those keywords (and their collocates) whose specific local lexical meanings and associated discourse structures. The final list of keywords analyzed was in the categories of employees (keywords colleague, colleagues, co-workers, employees, staff worker, workers), workplace (keywords-employer, employers, workplace). I generated 50 random concordances for each of the collocates of the keywords, which I will analyze in the subsequent sections.

\section{Employees}

This section focuses on representations of the employed, including experiences of the self-asemployee and the representation of others as employees. I will first analyze the generic nouns worker, workers, staff, and employees before analyzing the construction and representation of colleagues and co-workers.

\section{Worker/s}

With a Mutual Information (MI) score of 9.89, sex is the most significant collocate of workers - with MI 9.99, it is also the most significant collocate of worker. Although a particular arena of employment, analysis of concordances containing sex + worker is pertinent to understanding the cognitive organization experience, given that "many transgender women view the sex work industry as their only viable career option" (Nadal et al., 2014: 169) due to previous experiences of discrimination in more conventional workplaces. Indeed, the word trans modifies sex worker(s) in $14(28 \%)$ of the 50 random concordances of both sex + worker and sex + workers. Additionally, in 31 (62\%) concordances of trans + workers, gender-variant people are collectivized with sex workers as sharing similar needs in employment, including the need for workplace protections and rights. The focus when representing the paradigmatic 'trans person' and sex worker focus on deontic modality (e.g. should) regarding actions surrounding the rights of the collectivized group, specifically regarding the removal of rights by external agents (e.g. feminists, legislators). Seven occurrences within the 50 concordances of sex + worker constitute self-functionalization (see Van Leeuwen, 1996: 59) as a sex worker.

Additionally, and unsurprisingly, in concordances of rights + workers, sex workers are disproportionately represented as lacking rights (26 occurrences), over 'trans workers' rights' (2 occurrences), LGBT workers' rights (7 occurrences), and 'workers' rights' more generally (18 occurrences). Similar results were found in concordances of rights + worker. Hence, sex work is the dominant discourse in the cognitive organization of the actor-role of worker/s, though there are very few personal narratives of discrimination from users - as sex workers, or otherwise. Indeed, the near-absence of reference to 'trans workers' rights' indicates that gender-variance as a worker is less relevant than other social categorizations (i.e. sex workers) or employment rights in general. Are and is + worker/s also often reference sex work (18 occurrences - are + worker; 26 occurrences $-i s+$ worker $)$, though are + worker has a nearly equal 
number of occurrences (15) detailing more general aspects of employment, including a lack of wealth accumulation, the unionization of workers, and general inequalities faced by workers.

One alternative to the dominant discourse can be found in the collocation of social + worker. $12(24 \%)$ occurrences make reference to the user as occupying the role of social worker; while 17 occurrences refer to users' social workers and 18 to social workers more generally, this is evidence that the gender-variant user-population does consider viable alternative options for employment than sex work. Perhaps there is some correlation between the prevalence of reference to self-functionalization as social worker and the reference to utilizing the services of other social workers; this is potentially reflective of a shared cognitive model of vulnerability in the gender-variant user-population on Twitter - a reproduction, or internalization, of the hegemonic marginalization of gender-variant people.

\section{Staff and employees}

The pluralization and collectivization (Van Leeuwen, 1996: 49) of social actors via employees and staff is noticeable. Referents of staff in are + staff constructions are primarily public-sector workers (e.g. education, government, healthcare), and the collectivized group is not selfinclusive; collectivized via either specification or genericization (Van Leeuwen, 1996: 46-48), the staff of entire organizations and workplaces are bestowed the same characteristics whether positive or negative. This is a particularly interesting finding when exploring the organization of employment experiences within a theoretically shared gender-variant cognitive model; if the staff of particular organizations is collectivized and inherently shares characteristics, there is the implication that gender-variant individuals would consider themselves part of a collective in the workplace and contributors to the shared characteristic of the workforce.

This implication is reinforced in your + staff constructions. Such constructions frequently detail either positive or negative outcomes of experiences in retail or with other customer service staff (15 negative, 6 positive). The specific collective staff, which refers to all members of the workforce, is either granted praise for behaving in a manner that exceeds expectations or admonished for behaving inappropriately (from the user's perspective): all members of staff are the recipient of collective evaluation. The context of complaints or compliments in your + staff constructions may also enable further understanding of the validity of the studies reviewed herein. While six negative experiences were attributed to anti-transgender discrimination, there were no occurrences of explicit compliments on staff's trans-inclusive behavior (though it is implied in one occurrence). Thus, there is a potential implication for selfreport methods in research on gender-variant employment experiences: gender-variant individuals are predisposed to admonishing discriminatory behavior and not to highlighting trans-inclusive behavior, which would skew data towards negative employment experiences and outcomes. A lack of positive reinforcement of trans-inclusive behaviors might also indicate to external social actors (including employers) that any potential implementation of trans-inclusive policy or behaviors has no positive impact on employment experience.

Indeed, there are also other implications from your + staff constructions; namely, an implied reproduction of the power semantic between employers and staff. Eight occurrences include deontic modals that propose what employers are obliged to do in response to the either positive or negative interactions with individual members of staff. Ascribing duty to 
employers to either correct or praise their staff's behavior also ascribes power to employers and constitutes consent to the hegemonic hierarchy in the workplace: employers are responsible for their staff's actions, and for responding to those actions appropriately (e.g. via discipline, or praise). On a purely lexical level, your is a possessive pronoun; its co-occurrence with staff indicates the employer's possession of staff, and arguably the possession of responsibility over staff conduct. This is a potential reason for the ascription of blame to employers, by researchers and respondents, for the negative employment experiences of gender-variant employees and may explain some of the conclusions in the previously reviewed studies. A similar ascription of power semantic in the workplace context, and employers' responsibility over employment experiences, is also evident in your + employees constructions, though this is less about specific instances of employee behavior and more so about the general treatment of employees (including benefits, training) - however, there is very little reference specifically to gender-variant employees. Unlike your + employees constructions, co-occurrences of their and employees do not use deontic modality to propose that employers fix specific workplace issues. Instead, such constructions serve to highlight those employment issues, and via the use of epistemic non-modality commit to the absolute truth of the propositional content of the posts.

In terms of the practical realities of employment, employees + have constructions indicate workplace benefits or positive workplace outcomes on the part of gender-variant employees in 7 (14\%) occurrences, whilst indicating negative experiences, outcomes or policy in only 3 $(6 \%)$ occurrences. Such occurrences are either marked by the possession of benefits/outcomes by gender-variant employees, or by deontic modal 'have to' on the part of employers (who should, and are sometimes required by law, to enact positive policy and implement benefits). This is reflective of the cognitive organization of the roles of social actors in the context of employment: employers are agents in implementing workplace behavior, whilst employees are passive beneficiaries or recipients of such action. Co-occurrences of are and employees further reinforce this interpretation: employees are the agentialized in social action (see Van Leeuwen, 1995) in 11 occurrences, and the object of social action in 23 (36\%) occurrences, which indicates a cognitive model that reproduces the hegemony of reduced agency on the part of employees and the workplace power semantic. However, this does not always co-occur with negative outcomes. Indeed, in trans + employees constructions, there are 27 (54\%) positive implications for 'trans employees' and 22 (44\%) negative, despite gender-variant workers being constructed as the recipient of social action in 47 occurrences. Further, in transgender + employees co-occurrences, there is an overwhelmingly positive bent: 37 (78\%) occurrences refer to positive implications, and only $8(16 \%)$ to negative, despite 'transgender employees' being the recipients of social action in 42 occurrences. Such positive implications include legislation enforcing healthcare provision and workplace protections for gender-variant employees. Perhaps one of the implications of these findings is that the identifier used to refer to gendervariant employees is a factor in (the perception of) employees' treatment, whether positive or negative: transgender correlates more positively with positive practical realities in the workplace.

\section{Colleagues and co-workers}

Constructions including co-occurrences of $m y$ and the collective specification of social actors as colleagues overwhelmingly describe positive personal interactions with colleagues -36 
$(72 \%)$ positive interactions, $3(6 \%)$ negative interactions, and $9(18 \%)$ neutral interactions with no evaluative element. Out of those three constructions denoting negative personal interactions, two bear no relevance to the users' gender identity. This is particularly telling about the cognitive organization of gender-variant employees' workplace experiences: interactions with colleagues are generally positive. This corroborates the findings of Budge et al. (2010), who found that co-workers treated gender-variant employees more positively than expected. I + colleagues constructions yield similar results, with 20 occurrences detailing positive interactions/relationships with colleagues and only 4 negative. In fact, more (8) were neutral descriptive accounts of colleague behavior than were negative interactions/relationships with colleagues. Interestingly, co-occurrences were largely equal in whether they primarily pertained to feelings (i.e. relationships, emotion) or practical experiences (i.e. behavior) - 12 and 16 occurrences, respectively. The finding that users' interactions with colleagues are overwhelmingly positive is further reinforced by cooccurrences of colleagues with are and have. Colleagues are positive towards users or do positive things in the workplace generally (20 [40\%] occurrences, as opposed to $6[12 \%]$ negative), and have positive traits/characteristics/behaviors or have done positive things. However, the differences in a number of occurrences between positive and negative interactions in have + colleagues constructions is less significant -22 occurrences detailed positive interaction, and 16 negative.

Our and your + colleagues constructions are composed mainly of retweets from corporate Twitter accounts, or are posts made on behalf of a company. Whilst this may not seem particularly relevant to the aims of this research, it does, in fact, reveal additional information on the cognitive organization of the employment experiences of gender-variant individuals: posting on behalf of, or retweeting the posts of, an organization for which a user works implies solidarity and their identity with the entirety of the employer/organization's employees. Other co-occurrences of our and your + colleagues include references to friends and family, likening colleagues to friends and family. Again, this is useful in understanding the role employment plays in the social organization of users' lives: colleagues are linked with friends and family (in much the same way as gender-variant people and sex workers are linked elsewhere in the data) as constants in users' social networks with whom they are expected, and they consent to, interact with and assume solidarity. This is further reinforced by their + colleagues constructions, which explicitly refer to such (arguably) negative concepts as death but can indicate positive relationships of solidarity between colleagues.

My + colleague constructions, which detail positive interaction in 10 co-occurrences and negative interaction in eight co-occurrences, present a conflict in the findings. Negative interactions with a specified (Van Leeuwen, 1996) singular colleague are primarily grounded in negative behavior/action, whilst positive interactions with a specified singular colleague denotes solidarity with that colleague - often pride at standing or working with that colleague. This might constitute an implication for research on gender-variant experiences of employment insofar as employees may recount more positive experiences with colleagues if not primed to consider discrimination (either explicitly through the use of leading questions, or implicitly via the aims of the study), and more negative experiences if primed. It appears that, despite the implications of my + colleague constructions, specified colleagues are often represented positively: $40(80 \%)$ of friend + colleague co-occurrences specifically use the construction 'friend and colleague', which indicates that professional relationships are often 
also positive personal relationships (thus, reinforcing the finding that colleagues exist within the same social network and realm as friends and family).

The findings are consistent in between the above discussion of my + colleagues constructions and $m y+c o$-workers constructions - the latter's contain 18 positive interactions, and only 8 negative, indicating primarily positive relationships and interactions with co-workers. When co-workers and are co-occur, the findings are more negative than positive (11 [22\%] occurrences and 7 [14\%] occurrences, respectively). However, when discussing co-workers in relation to the self, via me $+c o$-workers, there is an indication of primarily positive interaction (16 positive, 8 negative co-occurrences). Indeed, in out + co-workers constructions, there are 11 positive experiences of either 'being' or 'coming out' as gender-variant in the workplace in comparison to only 2 negative experiences. This is particularly interesting in exploring the gender-variant employment experiences of gender-variant users - 'coming out' in the workplace can be a positive interactional experience with co-workers, and may have implications for how gendervariant employees navigate 'coming out' at work.

\section{The workplace}

This section focuses on representations of the workplace, including experiences of relationships with and feelings about employers. I will first analyze the generic nouns workplace, before finalizing the analysis by exploring concordances of employer and employers (with their collocates).

\section{Workplace}

Workplace collocates with LGBT 133 times. Their co-occurrences pertain primarily to positive action taken by various agents to improve the workplace experiences of those subsumed under the collectivized classification (Van Leeuwen, 1996) of LGBT (20 occurrences indicate positive action, whilst 13 indicate negative action). Such actions include the support of legislation regarding workplace rights for LGBT-identified workers, either negative or positive, or training for employers who wish to improve workplace rights for LGBT-identified workers in their specific organization, which we are invited to respond to positively. Despite 17 calls to action or representations of action of other agents, LGBT-identified users are only called to action or represented as agentive in such processes in 3 occurrences. Perhaps this also implies a reproduction of the hegemonic marginalization and non-agency of non-normative sexual identities, or another ideological belief that it is the role of legislators, elected officials, and employers (rather than those directly affected) to ameliorate the workplace situations of LGBTidentified employees.

The primary focus of $L G B T+$ workplace constructions is (anti-)discriminatory practices. This, and the lack of onus on gender-variant individuals to work towards ameliorating their own experiences, are consistent with constructions of workplace + discrimination. There are 0 cooccurrences of workplace and discrimination that reference a specific personal experience of discrimination; rather, the abstracted distillation of 'workplace discrimination' implies that, in the shared cognitive model of gender-variant users, it is not important what specific forms discrimination takes; rather, it is important that discrimination takes place (see Van Leeuwen, 1995: 99). However, without even anecdotal evidence, it is difficult to verify just how pervasive 
workplace discrimination is against 'transgender' and 'LGBT' employees. Indeed, in trans + workplace constructions, positive workplace interactions, outcomes, and policies are cited more often (21 occurrences) than discriminatory practices (12 occurrences).

Where personal experience of the workplace is cited, in constructions where workplace cooccurs with $m y$, workplaces are represented as positive, and there is a near-equal representation of gender-variant employees' action and others'. Hence, gender-variant employees are represented as agentive in personal workplace experience, but not in abstracted and genericized experiences of the workplace. This may constitute a particularly important finding in research on gender-variant experiences of the workplace: that gender-variant individuals can play a role in ameliorating their personal experience of employment, though they maintain a cognitive understanding of abstracted amelioration of workplace experiences as the domain of employers, legislators, and policy makers. There might also be some confusion as to the general abstracted needs of gender-variant individuals when compared with the needs of the larger collectivization LGBT: workplace + equality constructions more often than not collectivize gender-variant individuals within larger categories (29 [58\%] occurrences of collectivization, mostly with LGBT; 8 [16\%] occurrences of reference to trans-specific 'workplace equality'). This pattern is replicated in rights + workplace constructions (33 occurrences group gender-variant people with others, and only 11 refer specifically to gendervariant workplace rights). Hence, the positive personal and individual representations of workplace may be dependent on employees' ability to either explicitly or implicitly state their individual needs, whereas when workplace equality and rights are abstracted (such as at the level of legislation, or workplace policy), the needs of individuals are not as closely accommodated, leading to negative workplace experiences and outcomes. The implications are manifold: primarily, though, this may imply that gender-variant workplace experiences will be more positive if gender-variant employees take charge of their individual needs in the workplace, rather than awaiting policy change from above.

\section{Employer/s}

As with most other constructions, where the subjective possessive pronoun my co-occurs with a keyword, the resulting random concordances are primarily denotive of personal experience. However, unlike co-worker and colleague relations, personal narratives about the relationships and interactions between users and employer/s are more negative (10 occurrences - employers; 20 - employer) than positive (6 occurrences - employers; 12 - employer). Negative workplace outcomes, such as job loss, are attributed to employers' responses to gender identity and transition - without evidence (as in Budge et al. [2010]). Whilst some outcomes might denote or imply bad management practice, there is no way of verifying the claims in this dataset that negative workplace outcomes are the result of anti-transgender discrimination. However, it is accurate to state that gender-variant employees assume their gender identity is the root cause of negative workplace outcomes, and might be inferred that gender-variant users are engaging in the reproduction of hegemonic gender-variant marginalization.

The concept of discrimination is also present in co-occurrences of can + employers, which primarily pertain to the discussion on whether or not genericized employers can discriminate against non-heterosexual or gender-variant employees on religious grounds. There is the implication of opposition between religious organizations and LGBT-identified individuals, which constitutes the creation of in- and out-groups. This may be a factor in some of the 
negative feelings gender-variant employees in the workplace - potential avenues for future research include exploring the effect of differences in the political and religious ideologies of employers on the gender-variant employment experience. When can + employers cooccurrences refers to positive action, it also refers to a change in existing practice; conversely, when can + employers refers to negative action, it also refers to a continuation of existing practice. This is reflective of the cognitive organization of employment experience on the part of gender-variant users insofar as it reflects their understanding of existing practice in employment as being discriminatory - having long-standing, or stable, beliefs about practices constitutes an ideology and may lead to expectations of negative or discriminatory action in the workplace, contributing to negative affects (see Irving, 2017) and an adversarial stance against legislators/policymakers/employers.

The positive circumstance of change is also reflected in trans + employers and people + employers; specifically, there is a reference to encouragement/legislative force for positive action from employers to accommodate gender-variant and other LGBT-identified employees. Again, this reflects a cognitive organization of employment: as earlier there was an implied hierarchy between employers and employees, so too is there an implied hierarchy between legislators and employers. That is, legislators have the power to force employers/organizations into positive action. Whilst legislators are mainly represented positively in movements towards workplace equality in people + employers and trans + employers constructions, employers + are cooccurrences represent employers as "doing bad", or engaging in negative practices - especially with reference to 'shabby' treatment of employees, questionable practices on religious grounds, and ethically dubious financial practices. Of course, such evaluations of bad practice are ideologically loaded and politically biased, which indicates that political affiliation or ideology may contribute to the evaluation of workplace experience as either positive or negative. This is reflected in be +employers constructions, in which gender-variant individuals use deontic and epistemic modality to refer to what employers should or could be.

Transgender + employers co-occurrences also show where ideology and hegemony and society. Occurrences have near-equal positive (11) and negative connotations (9). Again, there are claims of rejection from employers due to gender-identity status without evidence - the references here are not to job loss, however, but to perpetual unemployment. Conversely, the positively connoted posts refer to the positivity of enforced policy/training. There is evidence here of intra-transgender variance in employment experiences; this may be a geopolitical issue, given that some users refer specifically to the Australian Workplace Equality Index (AWEI): positive and negative employment outcomes may be influenced by geographical and political factors.

The positive calls for gender-variant individuals agency in their own experiences, implied in $m y+$ workplace constructions are reproduced in your + employer co-occurrences ( 9 times). Such constructions confer agency to gender-variant individuals in workplace interactions, including in choosing whether or not to 'come out' and the notion that working for a specific employer is a conscious choice an individual makes (ergo, they can also choose not to work for that employer). You + employer further reinforces this, with users advising others to consider their own needs when deciding to work with an employer (e.g. healthcare), and whether those needs will continue to be fulfilled after the passing of specific legislation. Similarly, the action of gender-variant individuals is consistently referred to in trans + employer constructions (10 occurrences); however, this is specifically in response to the negative actions from 
employers/institutions and primarily involve civil lawsuits. Interestingly, only two distinct cases are evident in the 10 occurrences: users retweet information about the case - potentially as a means of endorsing the action or raising consciousness of the issue. This has potential implications for self-report methods, insofar as it implies that gender-variant individuals are willing to use other individuals' narratives for consciousness-raising - this might be especially true of activist participants, who have an ideological agenda to propagate. The promotion of action by gender-variant individuals to either ameliorate or seek compensation for negative workplace experiences and outcomes, regardless of ideology, implies that there is room for collaboration in improving workplace experiences for gender-variant individuals, where necessary.

\section{Conclusion}

This contribution sought to provide a three-fold contribution to research on gender-variant employment experiences. Firstly, I aimed to demonstrate the contribution corpus-driven linguistic analysis can make to understanding how gender-variant individuals either perpetuate or challenge workplace marginalization. Secondly, I aimed to explore the validity and reliability of using such a method to explore gender-variant employment experiences. The final contribution I intended to make was to explore the logical and ethical implications of attributing responsibility to societally dominant agents (i.e. employers, organizations, legislators). I will reflect on the degree of success to which I achieved these contributions in reverse order.

I explored ideological bias and logical fallacies in the process of drawing conclusions from premises (i.e. data) in previous studies on gender-variant employment experiences and found that several conclusions were not entailed by the data. The primary issue I raised was the attribution of blame or responsibility to organizations, employers and policymakers on the basis of gender-variant employees'/candidates' feelings, as opposed to practical reality. Not only is this logically unsound, but it is also ethically dubious. Removing agency from gendervariant individuals in the amelioration of their workplace experiences reproduces the hegemony many of the studies sought to challenge, and attributing blame where there is none only perpetuates antagonistic behavior to (prospective) gender-variant employees. By using a data-driven, rather than interpretation-driven, approach to the analysis of gender-variant individuals' employment experiences, I have provided preliminary evidence for the dualism between positive practical reality and negative (often fearful) emotional states. I have also provided preliminary evidence that gender-variant employees represent workplaces positively when they have taken action to ameliorate their own position (e.g. by 'coming out'). A potential contribution of this study to the logical and ethical implications of research on gender-variant employment experiences is the implication that a collaborative approach to amelioration would be more beneficial to all parties.

Using similar methods in sampling and observation to the studies reviewed herein, I have explained how corpus-driven linguistic analysis mitigates some of the response biases of selfreport and snowball/self-select sampling, which constitute threats to the validity of research. By analyzing existing empirical data using a data-driven approach, it is possible to control for biases in the design of research instruments and researcher ideology (to some extent). A thorough consideration of the threats to validity inherent in the approach enabled me to determine that there are still issues of external validity and reliability, but that these were 
mitigated somewhat by the methods: a corpus approach allows for a much more generalizable sample at least in terms of sample size - the sample of this study was within the range of the two averages of transmasculine and transfeminine population prevalence. Whilst this approach is by no means infallible, it constitutes a contribution to the field of research on gender-variant employment experiences insofar as it critiques and responds to previous studies in the area and their identified validity/reliability issues, providing implications for research practice. The results and discussion from the corpus-driven analysis also contribute to the research area, corroborating some results from previous studies, and providing potential explanations for some of the previous researchers' findings.

Not only has this contribution contributed to the scholarly discussion on ethics, logic, and research accuracy, but it has also contributed to the understanding of gender-variant employment experiences more generally. There is preliminary evidence that personal employment experiences are evaluated more positively than abstracted social practices. Additionally, the results point to the potential effects of identifiers (e.g. trans, transgender) on the positive or negative representation of experience. More specifically relevant to the intended contribution of identifying the role of gender-variant users' cognitive organization of workplace experiences in either perpetuating or challenging marginalization, I found preliminary evidence for consent to a hegemonic hierarchy in employment: employees are controlled and owned by employers, who are in turn controlled by legislators. There is also evidence of users' reproduction of the hegemonic marginalization of gender-variant people, representing themselves as largely non-agentive in workplace experiences, subject to the actions and agency of employers and institutions. Future research would consider certain variables further, including differences between gender-similar use-groups. Similarly, further research would explore deeper the relationships constructed and represented between social actors and their role in the cognitive organization of employment experience. Corpus-driven cognitive linguistics has many more potential applications for the research area.

\section{Keywords}

gender variant; corpus linguistics; Twitter; employment; sociocognitive discourse studies.

\section{Reference list}

Baker, P. (2014) Using Corpora to Analyze Gender, London: Bloomsbury.

Baker, P., Gabrielatos, C., KhosraviNik, M., Krzyżanowski, M., McEnery, T. and Wodak, R. (2008) “A Useful Methodological Synergy? Combining Critical Discourse Analysis and Corpus Linguistics to Examine Discourses of Refugees and Asylum Seekers in the UK Press", Discourse E Society, 19 (3): 273-306.

Bell, M.P., Özbilgin, M.F., Beauregard, T.A. and Sürgevil, O. (2011) “Voice, Silence, and Diversity in 21 ${ }^{\text {st }}$ Century Organizations: Strategies for Inclusion of Gay, Lesbian, Bisexual, and Transgender Employees", Human Resource Management, 50 (1): 131-146.

Bethlehem, J.G. (2010) "Selection Bias in Web Surveys", International Statistical Review, 78 (2): 161-188. 
Biernacki, P., Waldorf, D. (1981) "Snowball Sampling: Problems and Techniques of Chain Referral Sampling", Sociological Methods E Research, 10 (2): 141-163.

Brewster, M.E., Velez, B., DeBlaere, C. and Moradi, B. (2012) “Transgender Individuals' Workplace Experiences: The Applicability of Sexual Minority Measures and Models", Journal of Counseling Psychology, 59 (1): 60-70.

Brewster, M.E., Velez, B.L., Mennicke, A. and Tebbe, E. (2014) "Voices from Beyond: A Thematic Content Analysis of Transgender Employees' Workplace Experiences", Psychology of Sexual Orientation and Gender Diversity, 1 (2): 159-169.

Budge, S.L., Tebbe, E.N., Howard, K.A.S. (2010) “The Work Experiences of Transgender Individuals: Negotiating the Transition and Career Decision-Making Processes", Journal of Counseling Psychology, 57 (4): 377-393.

Cheng, J. (1996) “The Fundamental Role of Entailment in Knowledge Representation and Reasoning", Journal of Computing and Information, 2 (1): 853-873.

Danieli, A., Woodhams, C. (2005) “Emancipatory Research Methodology and Disability: A Critique", International Journal of Social Research Methodology, 8 (4): 281-296.

Davis, D. (2009) “Transgender Issues in the Workplace: HRD's Newest Challenge/Opportunity", Advances in Developing Human Resources, 11 (1): 109-120.

De Cuypere, G., van Hemelrijck, M., Michel, A., Carael, B., Heylens, G., Rubens, R., Hoebeke, P. and Monstrey, S. (2007) "Prevalence and Demography of Transsexualism in Belgium", European Psychiatry, 22 (3): 137-141.

Dietert, M., Dentice, D. (2009) “Gender Identity Issues and Workplace Discrimination: The Transgender Experience", Journal of Workplace Rights, 14 (1): 121-140.

Dietert, M., Dentice, D. (2015) "The Transgender Military Experience: Their Battle for Workplace Rights", Journal of Workplace Rights, 5 (2): 1-12.

Dispenza, F., Watson, L.B., Chung, Y.B. and Brack, G. (2012) “Experience of Career-Related Discrimination for Female-To-Male Transgender Persons: A Qualitative Study", The Career Development Quarterly, 60 (1): 65-81.

Donaldson, S.I., Grant-Vallone, E.J. (2002) “Understanding Self-Report Bias in Organizational Behaviour Research", Journal of Business and Psychology, 17 (2): 245-260.

Dunson III, M. (2001) “Sex, Gender, and Transgender: The Present and Future of Employment Discrimination Law", Berkeley Journal of Employment \& Labor Law, 22 (2): 465-506.

Gabrielatos, C., Baker, P. (2008) “Fleeing, Sneaking, Flooding: A Corpus Analysis of Discursive Constructions of Refugees and Asylum Seekers in the UK Press, 1996-2005", Journal of English Linguistics, 36 (1): 5-38.

Göçmen, İ., Y1lmaz, V. (2016) “Exploring Perceived Discrimination among LGBT Individuals in Turkey in Education, Employment, and Health Care: Results of an Online Survey", Journal of Homosexuality, 64 (8): 1052-1068.

Golafshani, N. (2003) "Understanding Reliability and Validity in Qualitative Research", The Qualitative Report, 8 (4): 597-606. 
Grant, J.M., Mottet, L.A., Tanis, J., Harrison, J., Herman, J.L. and Keisling, M. (2011) Injustice at Every Turn: A Report of the National Transgender Discrimination Survey, Washington, DC: National Center for Transgender and National Gay and Lesbian Task Force.

Hardaker, C., McGlashan, M. (2016) ““Real Men Don't Hate Women”: Twitter Rape Threats and Group Identity", Journal of Pragmatics, 91: 80-93.

Irving, D. (2017) “Gender Transition and Job In/Security: Trans* Un/Der/Employment Experiences and Labour Anxieties in Post-Fordist Society", Atlantis, 38 (1): 168-178.

James, S.E., Herman, J.L., Rankin, S., Keisling, M., Mottet, L. and Anafi, M. (2016) The Report of the 2015 U.S. Transgender Survey, Washington, DC: National Center for Transgender Equality.

Khamis, S., Ang, L., Welling, R. (2017) “Self-Branding,'Micro-Celebrity' and the Rise of Social Media Influencers", Celebrity Studies, 8 (2): 191-208.

Lakoff, G. (1987) Women, Fire, and Dangerous Things, Chicago, IL: University of Chicago Press.

Lather, P. (1986) "Issues of Validity in Openly Ideological Research: Between a Rock and a Soft Place", Interchange, 17 (4): 63-84.

Lavrakas, P.J. (2008) Encyclopedia of Survey Research Methods, London: SAGE.

Law, C., Martinez, L.R., Ruggs, E.N., Hebl, M. and Akers, E. (2011) “Trans-Parency in the Workplace: How the Experiences of Transsexual Employees Can Be Improved", Journal of Vocational Behavior, 79 (3): 710-723.

Lemon, M.C. (2003) Philosophy of History: A Guide for Students, London: Routledge.

Leskovec, J. and Krevl, A. (2014) SNAP Datasets: Stanford Large Network Dataset Collection. Available online at http://snap.stanford.edu/data (last accessed: January 16, 2018).

McEnery, T. and Hardie, A. (2012) Corpus Linguistics: Method, Theory and Practice, Cambridge: Cambridge University Press.

Mizock, L., Mueser, K. T. (2014) “Employment, Mental Health, Internalized Stigma, and Coping with Transphobia among Transgender Individuals", Psychology of Sexual Orientation and Gender Diversity, 1 (2): 146-158.

Mizock, L., Woodrum, T.D., Riley, G., Sotilleo, E.A., Yuen, N. and Ormerod, A.J. (2017) "Coping with Transphobia in Employment: Strategies Used by Transgender and Gender-Diverse People in the United States", International Journal of Transgenderism, 18 (3): $282-294$.

Nadal, K.L., Davidoff, K.C., Fujii-Doe, W. (2014) "Transgender Women and the Sex Work Industry: Roots in Systemic, Institutional, and Interpersonal Discrimination", Journal of Trauma \& Dissociation, 15 (2): 169-183.

Office for National Statistics (2016) Overview of the UK Population: February 2016. Available online

https://www.ons.gov.uk/peoplepopulationandcommunity/populationandmigration/po pulationestimates/articles/overviewoftheukpopulation/february2016 (last accessed: January 16, 2018). 
Overton, J., van Diermen, P. (2014) "Quantitative Research", In Development Field Work: A Practical Guide, R. Scheyvens (ed.), pp. 39-58, London: SAGE.

Ozturk, M.B., Tatli, A. (2016), “Gender Identity Inclusion in the Workplace: Broadening Diversity Management Research and Practice through the Case of Transgender Employees in the UK", The International Journal of Human Resource Management, 27 (8): 781-802.

Paulhus, D.L., Vazire, S. (2007) "The Self-Report Method", In Handbook of Research Method in Personality Psychology, R.W. Robins, R.C. Fraley and R.F. Krueger (eds), pp. 224-239, New York, NY: Guilford.

Rayson, P., Garside, R. (2000) “Comparing Corpora Using Frequency Profiling”, In Proceedings of the Workshop on Comparing Corpora, held in conjunction with the $38^{\text {th }}$ annual meeting of the Association for Computational Linguistics (ACL 2000), Hong Kong, Japan, October 1-8.

Richman, W., Kiesler, S., Weisband, S. and Drasgow, F. (1999) "A Meta-Analytic Study of Social Desirability Distortion in Computer-Administered Questionnaires, Traditional Questionnaires, and Interviews", Journal of Applied Psychology, 84 (5): 754-775.

Schilt, K., Connell, C. (2007), “Do Workplace Gender Transitions Make Gender Trouble?”, Gender, Work \& Organization, 14 (6): 596-618.

Spector, P.E. (1994) “Using Self-Report Questionnaires in OB Research: A Comment on the Use of a Controversial Method", Journal of Organizational Behavior, 15 (5): 385-392.

Statista (2018) Number of Monthly Active Twitter Users Worldwide from $1^{\text {st }}$ Quarter 2010 to $3^{\text {rd }}$ Quarter 2017 (in Millions). Available online at https://www.statista.com/statistics/282087/number-of-monthly-active-twitter-users/ (last accessed: January 16, 2018).

Tognini-Bonelli, E. (2001) Corpus Linguistics at Work, Amsterdam: John Benjamins Publishing Company.

United States Census Bureau (2017) National Population Totals and Components of Change: Data. Available online at https://www.census.gov/data/datasets/2017/demo/popest/nationtotal.html (last accessed: January 16, 2018).

van Dijk, T.A. (2009) “Critical Discourse Studies: A Sociocognitive Approach”, In Methods for Critical Discourse Analysis (2 ${ }^{\text {nd }}$ edn.), R. Wodak and M. Meyer (eds), pp. 62-86, London: SAGE.

van Dijk, T.A. (2015) "Critical Discourse Studies: A Sociocognitive Approach", In Methods for Critical Discourse Analysis (3 ${ }^{\text {rd }}$ edn.), R. Wodak and M. Meyer (eds), pp. 62-85, London: SAGE.

van Dijk, T.A. (2017) “Socio-Cognitive Discourse Studies”, In The Routledge Handbook of Critical Discourse Studies, J. Flowerdew (ed.), pp. 26-43, Abingdon: Routledge.

van Leeuwen, T. (1995) “Representing Social Action”, Discourse E Society, 6 (1): 81-106.

van Leeuwen, T. (1996) “The Representation of Social Actors”, In Texts and Practices: Readings in Critical Discourse Analysis, C.R. Caldas-Coulthard and M. Coulthard (eds), pp. 32-70, Abingdon: Routledge. 
Volkova, S., Backrach, Y., Armstrong, M. and Sharma, V. (2015) "Inferring Latent User Properties from Texts Published in Social Media", In Proceedings of the Twenty-Ninth Conference of the Association for the Advancement of Artificial Intelligence (AAAI 2015), Austin, TX, January 25-30.

World Professional Association for Transgender Health (2011) Standards of Care: For the Health of Transsexual, Transgender, and Gender Nonconforming People (7 $7^{\text {th }}$ Version). Available online https://www.wpath.org/media/cms/Documents/SOC\%20v7/SOC\%20V7_English.pdf (last accessed: January 16, 2018). 